\title{
NOÉMIA DE SOUSA E CONCEIÇÃO LIMA: VOZES FEMININAS QUE LUTAM PELA LIBERDADE E RECONSTRUÇÃO DE SEUS PAÍSES
}

\author{
NOÉMIA DE SOUSA AND CONCEIÇÃO LIMA: FEMALE VOICES FIGHTING FOR THE \\ FREEDOM AND RECONSTRUCTION OF THEIR COUNTRIES
}

\author{
Maria Cleunice Fantinati da Silva \\ Docente do IFMT, campus avançado Tangará da Serra; \\ Doutoranda-PPGEL -Estudos Literários, UNEMAT. \\ maria.silva@tga.ifmt.edu.br
}

Marinei Almeida

Docente - PPGEL- Estudos Literários (UNEMAT); Doutora e Mestra em Letras (Estudos Comparados de Literaturas de Língua Portuguesa), Universidade de São Paulo - USP.

prof.marinei@gmail.com

\begin{abstract}
Resumo: Neste trabalho averiguamos semelhanças e divergências no processo de construção estética e temática das produções poéticas da moçambicana Noémia de Souza e da santomense Conceição Lima. Autoras, respectivamente, das obras Sangue Negro (1998) e A dolorosa raiz do micondó (2006), de onde foram selecionados os poemas que constituem o corpus desta pesquisa. O principal objetivo é, pois, averiguar os pontos em que as histórias dos países dos sujeitos-poéticos influenciaram nas temáticas individuais e/ou coletivas referentes às reconfigurações das memórias nas reconstruções de suas nações. A pesquisa, de cunho bibliográfico, apoia-se num repertório teórico que tem revelado o valor literário dos textos poéticos das escritoras. As análises revelam que as vozes poéticas das africanas Noémia de Souza e de Conceição Lima, apesar de pertencerem a países diferentes, entrelaçam-se na dor que compartilham com o coletivo a busca pela liberdade e reconstrução.
\end{abstract}

Palavras-chave: Noémia de Sousa; Conceição Lima; Memórias; Reconstrução.

\begin{abstract}
In this paper we analyzed similarities and divergences in the process of aesthetic and thematic construction of the poetic productions of the Mozambican Noémia de Souza and of the Santomean Conceição Lima. Authors, respectively, of the works Sangue Negro (1998) and A dolorosa raiz do micondó (2006), from where we selected the poems that made up the corpus of this research. The aim is to investigate the points where the histories of the countries of the poetical subjects influenced the individual and/or collective themes related to the reconfiguration of memories in the reconstructions of their nations. This is a bibliographic research based on a theoretical repertoire that has revealed the literary value of the writers' poems. The analyzes reveal that the poetic voices of the African women, Noémia de Souza and Conceição Lima, despite belonging to different countries, are intertwined in the pain that they share with the collective in search for freedom and reconstruction.
\end{abstract}

Keywords: Noémia de Sousa; Conceição Lima; Memoirs; Reconstruction. 


\section{Introdução}

Temos como propósito analisar alguns poemas das escritoras africanas Noémia de Sousa e Conceição Lima, na perspectiva de averiguar eventuais semelhanças e/ou divergência no processo de construção estética e temática. Pretendemos analisar os pontos em que as histórias dos países influenciaram na reconfiguração das memórias.

As histórias oficiais dos países africanos colonizados deixam de fora muitas vozes que, tendenciosamente, os discursos hegemônicos tentaram apagar. Os registros oficiais, sentenciados pelos colonizadores quanto ao que deveria ser escrito, propagam uma verdade absoluta sobre verdades já existentes na África. A literatura dá voz a esses vultos apagados na história escrita pelo colonizador. No contexto do colonialismo português, que perdurou até o momento da independência, em 1975, o escritor/poeta africano vivia entre as sociedades colônia europeia e africana. A poesia de resistência nasce do choque entre essas duas esferas, assume outras vozes e passa a ecoar o seu grito por liberdade e justiça em diversos espaços. Na literatura africana de língua portuguesa, grandes poetas enveredaram-se por esse caminho, como José Craveirinha (Moçambique), Agostinho Neto (Angola), Francisco José Tenreiro (São Tomé e Príncipe), Jorge Barbosa (Cabo Verde), Gabriel Mariano (Cabo Verde).

Também vozes femininas se levantaram, neste contexto, para lutar em busca daquilo que lhes foram tomados pelo colonizador. Dentre elas, encontramos poetas como Alda do Espírito Santo, considerada a 'grande dama' da literatura Santomense, com o seu comprometimento com a história da libertação do seu país. Conceição de Lima dá sequência ao seu projeto libertário e identitário. Outro nome é o de Noémia de Sousa, referenciada como "a mãe dos poetas Africanos”, em Moçambique.

\section{Configurações poéticas de Noémia de Sousa e de Conceição Lima}

As poetas Noémia de Sousa e Conceição Lima representam as vozes poéticas de duas gerações pertencentes à Literatura Africana de Língua Portuguesa. Enquanto esta se insere na contemporaneidade, que ainda demanda reconstrução, com uma poesia que nasce no pós-lutas pela independência das nações africanas, aquela representa a inspiração de várias gerações de poetas moçambicanos.

Carolina Noémia Abranches de Sousa nasceu em 20 de setembro de 1926, em Catambe, vila no litoral Sul de Moçambique, banhada pelo Oceano Índico, na baía de Maputo. A poesia de Noémia de Sousa se insere no conjunto literário de Moçambique dos anos 1940-50 e, reivindicava a personalidade dos oprimidos e, deste modo, a literatura dos marginalizados. 
Nelson Saúte (1998), na introdução de Sangue Negro, diz que já havia lido sobre a poesia de combate, mas que desconhecia a extraordinária mulher, Noémia de Sousa, autora dos versos longos e belos. Longos o suficiente para expressar as misérias dos Munhuanas ${ }^{1} \mathrm{e}$ Xipamanines $^{2}$ onde moças fugitivas se acantonavam.

Sangue Negro, escrito entre 1948 e 1951, trata-se do único livro de Noémia de Sousa, publicado, visto que:

Cinquenta anos depois do abandono da escrita temos o beneplácito dos deuses e é este Sangue Negro e finalmente editado pela AEMO. Noémia de Sousa não o releu, nem o corrigiu, tendo concordado que os poemas permaneceriam na versão (original) policopiada, que se encontra depositada no Arquivo Histórico de Moçambique, devendo apenas ser actualizada a respectiva ortografia. [...]. Este livro transcende a condição de uma recolha de poemas. É, antes de tudo, um testemunho da nossa História. Neste volume ecoa uma voz, uma bela voz. Sobre esta voz ressoam outras vozes. [...]. (SAÚTE,1998, p. 23).

O livro é composto por 46 poemas de resistência organizados em seis seções, quais sejam: "Nossa Voz" (com seis poemas), "Biografia" (com oito poemas), "Munhuana 1951" (com 14 poemas), "Livro de João" (com seis poemas), "Sangue Negro" (com nove poemas) e "Dispersos" (com três poemas).

Maria da Conceição Costa de Deus Lima, nasceu em Santana, na ilha de São Tomé e Príncipe, em 1961. Em seu país fez os estudos primários e secundários e em Portugal estudou jornalismo. Licenciada em Estudos Afro-Portugueses e Brasileiros, pelo King's College de Londres, e mestre em Estudos Africanos, pela School of Oriental and African Studies (SOAS), de Londres, onde reside e trabalha como jornalista e produtora dos serviços de Língua Portuguesa da $\mathrm{BBC}^{3}$. Tem publicado três livros de poesia: O útero da casa (2004), A dolorosa raiz do micondó (2006) e O país de Akendenguê (2011).

\section{Noémia de Sousa: a voz feminina na representação coletiva do povo moçambicano}

Noémia de Sousa refere-se a voz feminina e fundadora da poesia em Moçambique que atravessa mares e assume a representação coletiva no mundo. Sua produção literária pertence à década de 50 e impressiona pela atualidade expressa em seus versos, depois de mais de meio século. O poder de atualização de sua poesia advém, provavelmente, do fato de sua poesia ser

\footnotetext{
${ }^{1}$ Grande bairro suburbano do Maputo. Munhuana 1951, título do terceiro capítulo do livro "Sangue Negro"

2 Bairro ou mercado pobre suburbano.

3 Informações extraídas da orelha da capa do livro (parte final), (LIMA,2004).
} 
a expressão de posicionamento em prol dos que lutaram e clamaram pela liberdade dos oprimidos durante o colonialismo português, entre os anos 1940 e 1975.

Segundo Laranjeira:

[...] A sua poesia surge nos antípodas de um Ricardo Reis, heterônimo pessoano, ou dos simbolistas. Emerge como uma espécie de lamento piedoso e revoltado contra a escravidão e o racismo, a dominação e exploração coloniais, a desigualdade econômica e social.[...]. (LARANJEIRA, 2006, p. $33)$.

O primeiro poema de Noémia de Sousa, publicado em 1948, no jornal O Brado Africano "Canção Fraterna" foi assinado apenas com as iniciais N.S. e, canta a dor que também é do outro. Apesar da inocência que o poema aparenta na atualidade, deve-se levar em consideração o ano da publicação, pois Moçambique ainda estava submisso ao colonialismo português. É nesse contexto, que a jovem poeta, com seus 22 anos, teve coragem para se colocar em confronto aos opressores e dominadores da época, como assinalado por Saúte (1998, p.11). Desse modo, o eu-poético inicia a luta pela liberdade da terra invadida pelo colonizador com "Canção Fraterna".

Irmão negro de voz quente o olhar magoado,

diz-me:

Que séculos de escravidão

geraram tua voz dolente?

Quem pôs o mistério e a dor em cada palavra tua?

E a humilde resignação

na tua triste canção?

E o poço de melancolia

No fundo do seu olhar?

Foi vida? o desespero? o medo?

Diz-me aqui, em segredo, irmão negro.

Porque a tua canção é sofrimento

e a tua voz sentimento

e magia.

Há nela a nostalgia

da liberdade perdida,

a morte das emoções proibidas,

e a saudade de tudo que foi teu

e já não é.

Diz-me, irmão negro,

Quem fez a vida assim...

Foi a vida? o desespero? o medo? 
Mas mesmo encadeado, irmão, que estranho feitiço o teu!

\author{
A tua voz dolente chorou \\ de dor e saudade, \\ gritou de escravidão e veio murmurar à minha em alma ferida \\ que a tua triste canção dorida \\ não é só tua, irmão de voz de veludo \\ e olhos de luar... \\ Veio, de manso murmurar \\ que a tua canção é minha.
}

(Sousa, 1998, p. 74-75)

O tema central do poema Canção "Fraterna" é a subjugação do homem negro gerada pelos anos de escravidão. O título do poema, segundo Sousa, (2008) é uma antecipação ao leitor da intenção do eu-poético em estabelecer laços de união em torno do ideal de solidariedade, no compartilhar do sofrimento do outro que se trata do próprio irmão.

A poética de Noémia de Sousa une-se à tristeza dos moçambicanos que apesar de magoados não reagem. Seus versos prontificam-se para iniciar um diálogo com seu irmão negro. O irmão negro, no contexto da produção do poema, é a representação do povo moçambicano. O questionamento do início do poema tem por intuito despertá-lo, acordá-lo para a situação em que se encontra o país. Os versos seguidos de interrogações têm a intencionalidade reflexiva. Chamamento para um despertar do silenciamento ao qual o opressor impôs ao povo, colocando-o na condição de aceitação, de imobilidade. Também anunciam a indignação do eu-poético com os séculos de escravidão e o conformismo de seu povo.

As indagações prosseguem nos tercetos que intercalam as estrofes de oito versos. A voz poética evoca a memória do seu interlocutor coletivo, “o irmão negro", para uma conversa em segredo: "Diz-me". O eu-poético rememora fatos históricos relacionados à escravidão, posto que visa a potencialização de uma ancestralidade. Deste modo, manifesta o desejo de unir seu povo.

O passado deve ser rememorado, pois tudo pode-se perder no esquecimento. O eupoético evoca o irmão negro (coletivo) para rememorar o passado, pois só se pode modificar o futuro a partir da lembrança presente dos acontecimentos passados. O pensamento de Le Goff (1994), corrobora a memória como um item essencial na identidade de um indivíduo e de um povo.

\footnotetext{
4 Grifo nosso.
} 
É perceptível que a voz poética intenciona provocar a lembrança do passado na memória coletiva de seu povo para que não se perca no esquecimento. Entretanto,

Noémia utiliza-se desse artifício para que também a sua identidade moçambicana seja reforçada na luta contra a opressão colonial vivida por ela e seu povo. E é através dela que essa poeta pode levar o seu povo a lutar pela tão sonhada liberdade e amar mais a sua pátria mãe, África. (DANTAS et.al, 2009, p.126).

Nos versos que seguem, o eu-poético questiona o sofrimento na canção de seu povo. Afirma que há nostalgia na canção, na voz e na magia da liberdade perdida. Reconhece que, ao expressar tanta tristeza, o povo tem consciência de tudo que perdeu para o colonizador. Através da consciência de que um dia tiveram uma pátria, o eu-poético conclama seus irmãos, para que juntos rememorem tudo aquilo que lhes pertenceu e que um dia lhes tiraram. Deste modo, o primeiro poema de Noémia de Sousa, "Canção Fraterna" tematiza a subjugação do homem negro gerada pelos anos de escravidão.

Através das indagações individuais e coletivas "Canção Fraterna" faz uma tentativa de desenhar a situação do escravizado e canta a melodia da união, da fraternidade. Outros poemas de Sangue Negro também remetem à fraternidade, como ocorre em "Poema da Infância Distante", na segunda parte do livro, intitulada "Biografia". Nele há a valorização dos companheiros, pois “[...] Eles me provaram que "fraternidade" não é mera palavra bonita/ escrita a negro no dicionário da estante:/ ensinaram-me que "fraternidade" é um sentimento belo, e possível, [...]." (SOUSA, 1998, p. 53-54). Nesta perspectiva, a poética de Noémia de Sousa clama pela união do povo negro em prol da independência e contra a dominação do colonialismo.

O poema "Um dia", pertencente à quarta parte do seu livro, intitulada "Livro de João", anuncia a esperança revestida da certeza. O futuro é utópico, anunciado, a partir do título, uma independência vindoura. Seus versos convidam o "amigo" coletivo para um passeio pela Moçambique livre:

Quando $^{5}$ este nosso Sol ardente de África nos cobrir a todos com a benção do mesmo calor quero ir contigo, amigo, de mãos dadas, deslumbrados, pelos trilhos abertos de nossa terra estranha, adubada com sangue e o suor de séculos...

Nas machambas ${ }^{6}$,

\footnotetext{
${ }^{5}$ Grifo nosso.

${ }^{6}$ Lotes de terras, sítios, chácaras.
} 
o ruído repercutido de tractor soará como uma canção de triunfo.

Nas matas, as tutas já não serão aves apenas e no centro da vida, nosso irmão negro, quebradas as grilhetas, celebrará seu segundo nascimento num batuque diferente de todos os outros...

Uma luz clara e doce se abrirá para todos, e nós iremos de mãos dadas, amigo, pelos trilhos verdes de Moçambique.

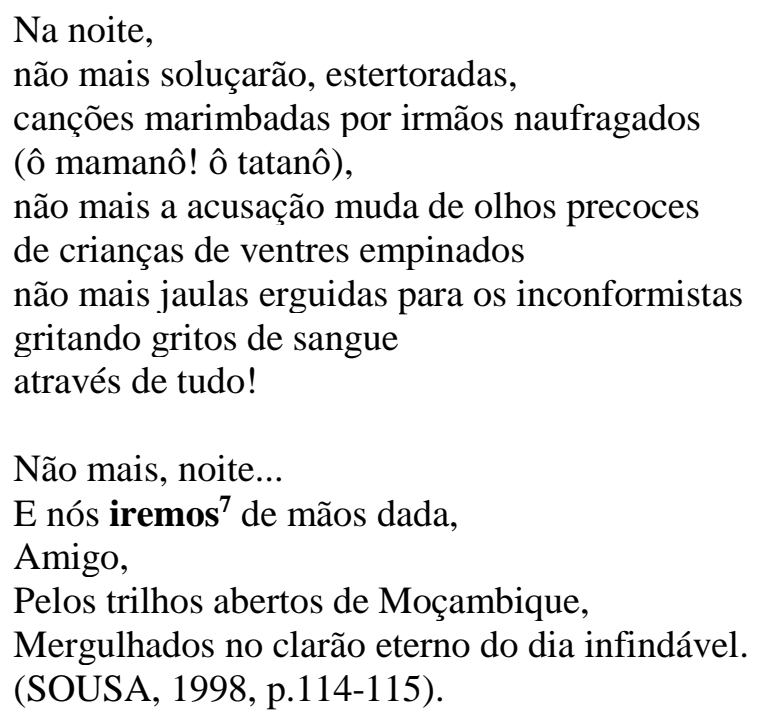

Ao iniciar o primeiro verso da primeira estrofe com uma conjunção subordinada temporal, a voz poética transmite a certeza da África livre. Também o pronome possessivo "nosso" e a palavra "Sol", escrita com letra maiúscula, marcam o pertencimento exclusivo do povo africano, tão acostumado com o "[...] nosso Sol ardente de África”. Assim como o Sol pertence a todos os africanos, a nação é de todos, pois, receberão "a benção do mesmo calor". Nota-se o desejo de que a igualdade e a fraternidade sejam recuperadas neste dia em que não mais existirá a segregação e todos serão amigos.

E, neste dia, de mão dadas, o eu-poético e o povo africano caminharão pelos trilhos abertos na terra que lhes pertence, mas estranha pela destruição advindas da colonização, da exploração e guerras. Esta estrofe marca, utopicamente, a reconquista da independência de Moçambique.

\footnotetext{
7 Grifo nosso.
} 
Na segunda estrofe, a poeta visualiza a terra livre do colonizador, ou seja, o país após a independência. Neste ponto, inicia-se uma viagem ao futuro, apontada pelos verbos conjugados no futuro do presente do indicativo. O ruído do trator soará como uma canção de triunfo e o povo africano, livre das argolas, poderá celebrar o segundo nascimento. O batuque será uma canção diferente de todas, pois cantarão a canção de liberdade e reconstrução do país.

$\mathrm{Na}$ terceira estrofe, o eu-poético apresenta uma nação reconstruída, o povo unido, de mãos dadas, seguindo "pelos trilhos verdes de Moçambique". Os trilhos, antes cobertos de sangue, voltarão a ter a cor de seu país. Na estrofe seguinte, a promessa de que jamais viverão na noite é a negação do desconhecido. O período do dia em que há ausência de claridade metaforiza o sofrimento, a dor e a exploração. Nestes versos predominam a rejeição a todo mal que o colonizador causou ao povo moçambicano. Durante a noite, não haverá mais exclamações que exprimam dor e desespero como outrora: (“ô mamanô! ô tatanô!”). Na última estrofe, os versos anunciam a felicidade infindável, pois, tanto a nação, quanto a liberdade lhes pertencem.

\section{Conceição Lima e a busca da árvore genealógica para a construção da nação}

A poética de Conceição Lima está vinculada à geração que recebe a herança da luta como patrimônio. Neste sentido, a sua poesia propõe a (re)construção da casa, ou seja, da nação. O eu-poético conclama seu povo para a reescrita de sua história: “Começarás de novo, insone/ com as mãos de húmus e basalto/ como que reescreve uma longa profecia" (LIMA, 2004, p. 22). A percepção da necessidade de reescrita da história do país, violada e desconstruída pelas marcas do colonizador, reivindica uma longa profecia. Então, o eu-poético invoca o povo para a reconstrução do passado visualizando o futuro. Em outras palavras, como uma predição do porvir. O título do livro, A dolorosa raiz de micondo ${ }^{8}$, metaforiza a busca pelos antepassados, ou seja, suas raízes. Secco considera que

A dolorosa raiz de micondó como uma alegoria das dores vividas pelos habitantes das ilhas em decorrência da opressão colonial; alude a uma árvore da flora local que viu chegarem ao Arquipélago, em 1470, João de Santarém e Pedro Escobar, mas resistiu através dos séculos (SECCO, 2018 p.295-296).

O primeiro poema, "Canto obscuro às raízes", é composto por 56 estrofes, ora longas, ora compostas por um único verso, denotam a busca incansável de um eu-poético, às vezes solitário e outras vezes coletivamente, por resgatar a ancestralidade. A voz poética anuncia que tem um projeto, ou seja,

\footnotetext{
${ }^{8} \mathrm{O}$ micondó, ou imbondeiro, é uma árvore considerada sagrada por muitos povos africanos. Espécie de baobá, é conhecida como árvore da vida, devido à sua incrível longevidade, que chega a seis mil anos.
} 
[...] busca descobrir suas raízes ancestrais como o fez o escritor norte americano Alex Haley, que segundo seus relatos, depois de 12 anos de procura encontrou a aldeia Juffure, localizada na atual Gâmbia, de onde seu ancestral Kunta Kinte foi arrancado pelos comerciantes negreiros [...] (LIMA, 2010, p.85 -86).

Nos dois primeiros versos, a poetisa inicia a viagem em busca de suas raízes: "Em Libreville/ não encontrei a aldeia do meu primeiro avô". Ao visitar a cidade de Libreville, capital da República Gabonesa, o eu-poético tem a sua primeira decepção, pois não encontra a aldeia de Juffere, local onde nasceu Kunta Kinte ${ }^{9}$. Mas, Alex Haley ${ }^{10}$, cidadão da Virginia, que era obstinado, "resgatou o caminho para Juffere/ a aldeia de Kunta Kinte / seu último avô africano/ primeiro na América", porque o escritor norte-americano, através dos arquivos de memórias dos griots ${ }^{11}$,

[...] reconstituiu biblicamente a trajetória de sua família, a partir das histórias repetidas por sua avó, depois de percorrer arquivos, bibliotecas, coleções de documentos oficiais e particulares, realizar várias viagens à África, particularmente a Gâmbia - terra dos mandingas, cujos contingentes também aportaram no Brasil - onde detectou os passos do seu parente Kunta Kinte que - mais que uma personagem - é o símbolo e o protótipo do preto capturado pelos negociantes negreiros (COSTA, 1976, p.11).

A família começa com o jovem Kunta Kinte capturado em Gâmbia, sua terra natal, e transportado em condições desumanas para a América colonial, onde é vendido como escravo e sua história atravessa várias gerações. Na poética de Conceição Lima, essa história é rememorada, pois não foi a única e certamente existem tantas outras que foram apagadas pela força opressora do colonizador branco. A poeta faz a reescrita da história de Kunta Kinte com o intuito de resgatar suas raízes, mas também de uma memória coletiva, posto que esta é uma dentre inúmeras famílias que foram brutamente separadas. Sobre a questão, Lima, pontua:

[...] como tantos outros descendentes do contingente de africanos que têm em comum na memória a ruptura familiar imposta pelo tráfico de escravizados a partir do século XV, ficando a maior parte das famílias sem a noção do lugar para onde seus antepassados foram levados. Esse esfacelamento familiar cortou as raízes, os laços de inúmeras gerações, desdobrando-se numa tangível perda identitária, uma forma de despersonalização (LIMA, 2010, p.86).

\footnotetext{
${ }^{9}$ Kunta Kinte nascido em 1750 na aldeia de Juffure na Gâmbia, na África Ocidental. Filho de Omoro e Binta Kebba. Aos 17 anos, Kunta Kinte é sequestrado e levado para os estados Unidos, para cidade de Maryland em um navio.

${ }^{10}$ Alexander Murray Palmer Haley (Alex Haley) (Ithaca, 11 de agosto de 1921 - Seattle, 10 de fevereiro de 1992) foi um escritor estadunidense. É conhecido principalmente por seus relatos sobre a escravidão. Sua obra mais conhecida é "Roots: The Saga of an American Family", publicado em 1976. Suas obras se baseiam principalmente nas histórias de sua própria família, faz uma interpretação da viagem do Africano kunta Kinte para a América durante o período da escravidão.

${ }^{11}$ Griots, Jeli ou Jali são indivíduos que tinham o compromisso de preservar e transmitir histórias, fatos históricos e os conhecimentos e as canções de seu povo.
} 
A poesia de Conceição Lima clama por uma reescrita da história do povo africano. De acordo com Mbembe (2014, p. 60), a escrita esforça-se para forjar a edificação de uma comunidade a partir de restos dispersos em todos os cantos do mundo. Cabe à escrita reconstituir o desenraizamento e esfacelamento que o colonizador impôs aos povos africanos. Porque, complementa Mbembe:

[...] No prolongamento da Emancipação e da Reconstrução, a reescrita da história é mais do que nunca, considerado um acto de imaginação moral. $\mathrm{O}$ gesto histórico por excelência consistirá doravante em passar do estatuto de escravo ao de cidadão como os outros. A nova comunidade, de homens livres, é agora concebida como a comunidade onde os membros e por uma certa ideia de trabalho e respeitabilidade, de dever moral, de solidariedade e de obrigação. (MBEMBE, 2014, p. 60).

A poesia, neste sentido, necessita intervir, pois a exploração ainda está impregnada em sociedades escravagistas que trazem o ranço do preconceito e da discriminação, implantada em suas raízes. A poeta assume o compromisso de (re)plantar "mincondós” em seu país.

O penúltimo poema da referida obra de Conceição Lima, "Soya", anuncia a esperança desta reconstrução. Segundo Lima (2010, p. 88), “O micondó irrompe com seu poder mítico e simbólico de guardar as lembranças deste universo, sinalizando para uma representação identitária local". O eu-poético, sensibilizado por essas lembranças simbólicas, busca rememorar, juntamente com povo são-tomense, valores pelos quais possam se reconhecer e se reconstruir. Assim, em "Soya"12, temos:

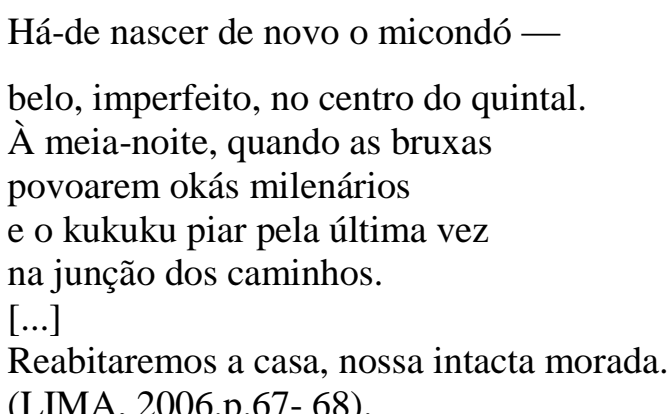

Na primeira estrofe, a poeta expressa a quase certeza de um futuro promissor para seu povo. O verbo 'haver', na terceira pessoa do singular, do presente do indicativo, seguido da preposição 'de' e do verbo 'nascer', na sua forma infinitiva, são indicativos dessa promessa. Deste modo, a locução verbal sugere a certeza do reencontro entre aqueles que foram separados no passado distante. Estes versos anunciam a esperança, pois um novo "micondó" nascerá no 
centro do quintal. Ou seja, debaixo da sombra do "micondó" as famílias voltarão a reunirem-se para recontarem suas histórias.

O eu-poético é a voz anunciadora da esperança, pois, à meia-noite, quando as bruxas retornarem para as "okás ${ }^{13 "}$ e o "kukuru ${ }^{14 "}$ piar pela última vez, acontecerá a junção dos caminhos. Enfim, o reencontro do eu-poético coletivo com suas raízes, na certeza de que "Reabitaremos a casa, nossa intacta morada".

Laranjeira, (2006, p. 36), observa que Conceição Lima assume na poesia o legado tradicional da cultura africana santomense. Como mulher, negra e filha deste país, posiciona-se contra a história de revoltas e contra o regime colonial. A poeta visualiza a esperança de futuro melhor em oposição ao presente de mentiras e continuidade da exploração do povo pelos políticos. Através de sua poesia ela se posiciona como a figura, hoje histórica. E este posicionamento é nitidamente perceptível no poema "Certos pequenos Tiranos", no qual, o eupoético critica personagens que se sujeitam à condição de vassalos. Lê-se:
[...] Por vezes articulam sentenças
E estão sempre em atritos com o mesmo orçamento.
[...]
tomam por amor a vénia dos vassalos/
os pequenos tiranos/
que publicam altos amigos como títulos de jornal/
e distribuem grãos de favor como quem outorga um foral/
são meticulosos no arrumar dos papéis/
pois na simetria das coisas enterram a luz das ideias.
(LIMA, 2006, p. 47-48).

Ora, no passado os africanos foram usurpados de todos os direitos, mas a poética de Conceição Lima posiciona tanto em prol do regaste de identidades por meio da memória, quanto do presente, ironizando os tiranos da atualidade. No poema, os tiranos são figuras universais, ou seja, os corruptos, os traficantes, exploradores. Enfim, os homens das leis ou representantes do povo que "Por vezes articulam sentenças". Entre passado e presente, poucas foram as transformações porque homens que premeditam levar vantagens não deixaram de existir. $\mathrm{Na}$ perspectiva de Memme, para libertar o colonizado é preciso antes libertar o colonizador. Porém, o colonizador vai tentar perpetuar esta relação, pois lhe é vantajosa, deste modo:

[...] Estrangeiro, chegado a um país pelos acasos da história, conseguiu não apenas um lugar, mas tornar o habitante, e outorgar-se privilégios surpreendentes em detrimento dos que a eles tinham direito. E, isso não é virtude das leis locais, que legitimam de certo modo a desigualdade pela

\footnotetext{
13 “Okás”, também conhecida por mafumeira; árvore associada no imaginário popular a forças maléficas, para cuja copa as bruxas desertam à meia - noite, segundo a crença popular.

14 "Kukuru", ave noturna, coruja.
} 
tradição, mas ao subverter as normas vigentes, substituindo-as pelas suas. (MEMME, 1977, p.25).

A poeta em questão posiciona-se contra a relação imposta pelo colonizador porque nesta relação o povo africano sempre foi explorado e marginalizado. Sua poesia coloca-se em defesa dos que foram calados pela força opressora do colonizador. Não diferentemente do ocorrido em outros países em que a liberdade foi oficialmente concretizada para os escravizados, mas os colonizadores portugueses mantiveram o trabalho escravo. $\mathrm{Na}$ área rural, essa situação perdurou por muito tempo chegando ao século XX. As consequências do colonialismo marcam a poética de Conceição Lima como forma de denúncia e, ao mesmo tempo, provoca a reflexão sobre a conscientização de seu povo.

No poema "O Vendedor" o sujeito poético denuncia a exploração do trabalho infantil em quatro pequenas estrofes. A estrutura das estrofes direciona para a criança que ainda pequena é explorada na sua inocência.

A estrofe composta por um único verso denuncia o espaço da exploração, qual seja: “A Feira do ponto é o seu pátio". Espaço frequentado por muitas pessoas que fecham seus olhos, denotando que o povo ainda está subordinado ao silêncio diante das injustiças. E, ao fim do dia, somente depois de ter cumprido sua tarefa, é que o vendedor volta a ser criança.

\footnotetext{
Os olhos vagalumem como pirilampos

no encalço dos fregueses

Do fio que é a mão esvoaçam

sacos de plástico

precários, multicores balões

A Feira do Ponto é o seu pátio.

Ao fim do dia, parcimonioso,

devolve a bolsa das moedas a um adulto

e recupera a idade.

(LIMA. 2006, p.43)
}

A breve descrição que o eu-poético faz do trabalho infantil tende a provocar, no leitor, uma reflexão. A cena corriqueira de crianças trabalhando da Feira do Ponto, mercado informal em São Tomé e Príncipe, não é percebida pelos transeuntes, mas pelo eu-poético que toma para seus versos um menino para representar tantos outros que dividem este espaço comercial onde "Os olhos vagalumem como pirilampos/ no encalço dos fregueses". Os olhos brilham revelando a fase infantil do menino numa mescla de criança e animal que se amalgama harmoniosamente. Mas o trabalho exige-lhe rapidez na perseguição dos fregueses. Segundo Aleixo, 
[...] estudos elaborados no ano de 2015 pela representante adjunta da Unicef para São Tomé e Príncipe, Ainhoa Jaureguieitia, as crianças, além de numerosas, compõem a parcela da população mais vulnerável. O trabalho infantil, o abuso sexual, o abandono, a desnutrição e o ambiente inóspito, devido à precariedade dos serviços de saneamento, consomem aquele ar lúdico, o qual deveria abastecer naturalmente a vida de qualquer criança, que Lima singelamente tenta reoxigenar no primeiro verso de "O vendedor". (ALEIXO, 2018, p. 62).

A existência da exploração do trabalho infantil incomoda o eu-poético que registra a denúncia em versos alvitrando elucubrações. No final do expediente o menino entrega o dinheiro a um adulto recuperando, só então, sua idade, ou seja, retornando à condição de criança. É perceptível que estamos diante de uma denúncia da exploração infantil.

\section{Considerações Finais}

A poesia de Noémia de Sousa assume o comprometimento com as causas da independência de Moçambique e convoca a participação da nação para a conquista do país. Para a libertação é preciso, antes de tudo, a união do povo moçambicano. A poeta deixa explícito esse comprometimento com a situação histórica, política e econômica de seu país. Seus poemas tematizam a negação da submissão ao colonialismo português.

A voz poética de Conceição Lima retoma o passado metaforizado na raiz do micondó, arraigada à memória pessoal. A poeta canta as dores e as dificuldades que os africanos e os afrodescentes têm para reconstruir as suas raízes familiares e étnicas.

Noémia de Sousa e Conceição Lima são fortemente marcadas pela realidade de seus respectivos países. Aquela assume a voz dos moçambicanos, silenciados historicamente, apontando para possibilidade da identidade, através da produção literária. Esta, tenta recompor a história do povo santomense buscando pela ancestralidade, ou seja, por suas raízes.

Assim como a poesia de Noémia de Sousa registra o desejo de liberdade e a certeza de um mundo fraterno, a poética de Conceição Lima almeja pela reconstrução identitária do povo São Tomé e Príncipe. A poeta santomense manifesta o desejo da reconstrução de seu país e, como a moçambicana, canta a esperança de um futuro promissor.

Entrelaçam-se a poesia da escritora moçambicana com a poesia da escritora santomense na dor compartilhada com o coletivo e, rememora fatos históricos estabelecendo vínculos sociais e culturais. Ambas parecem movidas pelo desejo de construir novas maneiras de organização social. Nos contextos em que estão inseridas, as vozes poéticas femininas buscam a construção de uma nova identidade que perpassa pelos sonhos e pelas memórias. 


\section{Referências}

ALEIXO, Camila Dias Souza Christo. Do micondó ao mangue[manuscrito]; desenterra a dolorosa raiz de Conceição Lima. Mariana: Universidade Federal de Ouro Preto, 2018.

COSTA, Haroldo. Nossas Negras Raízes. In: HALEY, Alex. Negra Raízes: a saga de uma família. Trad. de A. B. P. de Lemos. 9 ed. Rio de Janeiro: Record, 1976.

DANTAS, Luciana Neuma; BEZERRA, Rosilda Alves. Memória e sociedade: o sangue negro de Noémia de Sousa. In: LIMA Tânia; NASCIMENTO, Izabel; OLIVEIRA, Andrey (Org). Griots - culturas africanas: linguagem, memória, imaginário. Natal: Lucgraf, 2009. p.121127.

GLOSSÁRIO. Literaturas africanas de língua portuguesa. Plataforma Lusofonia. Disponível em: <http://lusofonia.x10.mx/glossario_africano.htm\#J>. Acesso: jun/2019.

LARANJEIRA, Jose Pires. Mulheres que escrevem: Noémia, Alda, Conceição, Chiziane. Veredas. n. 7, 2006, p. 31-39.

LE GOFF, Jacques. História e memória. Trad. de Bernardo Leitão; et al. 3 ed. Campinas: Editora da Unicamp, 1994.

LIMA, Conceição. A Dolorosa Raiz do Micondó. Lisboa: Caminho, 2006.

LIMA, Elizabeth Gonzaga. Paisagem e memória em A dolorosa raiz do micondó de Conceição Lima. Caderno Cespuc: Belo Horizonte, 2010. Disponível: http://periodicos.pucminas.br/index.php/cadernoscespuc/article/viewFile/7834/687ㅁ․ Acesso: 08/07/2019.

MBEMBE, Achille. Critique de la Raison Nègre. Trad. de Marta Lança. Crítica da Razão Negra. Portugal: Antígona, 2014.

MEMME, Albert. Retrato do Colonizado Precedido Pelo retrato do Colonizador. Tradução de Roland Corbisier e Marizza Pinto Coelho. 2 ed. Rio de Janeiro: Paz e Terra,1977.

SAÚTE, Nelson. Noémia de Sousa: A mãe dos poetas Moçambicanos. In.: SOUSA, Noémia. Sangue Negro. F. Mendonça \& N. Saúte (org.) Ed. Associação dos escritores Moçambicanos. Moçambique: CIEDIMA, 1998. p.11-12.

SECCO, Carmen Lucia Tindó. Três vozes Guerreira Femininas de São Tomé e Príncipe: D. Alda, Manuela Margarido, Conceição Lima. In: MATA, Inocência/ SILVA, Agnaldo Rodrigues da. Trajectórias culturais e literária das ilhas do Equador: Estudos sobre São Tomé e Príncipe. Campinas: Pontes Editores, 2018. p. 281-299.

SOUSA, Carla Maria Ferreira. Noémia de Sousa: Modulação de uma escrita em turbilhão. Revista África e Africanidades. Ano I, n. 1, mai/2008. Disponível em: <www.africaeafricanidades.com>. Acesso em: jun/2019.

SOUSA, Noémia. Sangue Negro. F. Mendonça \& N. Saúte (org.). Ed. Associação dos escritores Moçambicanos. Moçambique: CIEDIMA, 1998. 